\title{
Ground-active arthropod responses to rainfall-induced dune microhabitats in a desertified steppe ecosystem, China
}

\author{
LIU Rentao ${ }^{1,2 *}$, ZHU Fan ${ }^{1}$, Yosef STEINBERGER ${ }^{2}$ \\ ${ }^{1}$ Key Laboratory for Restoration and Reconstruction of Degraded Ecosystem in Northwestern China of Ministry of Education, \\ Ningxia University, Yinchuan 750021, China; \\ ${ }^{2}$ The Mina \& Everard Goodman Faculty of Life Sciences, Bar Ilan University, Ramat-Gan 52900, Israel
}

\begin{abstract}
Different microhabitats along dune slope were found to affect the distribution of plant performances and soil properties in desertified ecosystems. However, the ground-active arthropod responses to rainfall-induced dune microhabitats were largely unknown in desertified regions. At dune top, midslope and bottom, ground-active arthropods were sampled by the method of pitfall traps in addition to the herbaceous and soil measurements during spring, summer and autumn from 2012 to 2013. Ground-active arthropod had a strong dynamics in time, seasonally and yearly in responses to rainfall-induced dune microhabitats and the variations were significant higher than those of soil and herbaceous properties. The abundance distribution of dominant taxa (i.e. Melolonthidae, Carabidae, Glaphyridae, Tenebrionidae and Formicidae families) among dune microhabitats was similar between seasons within the same year, whereas they differed markedly between two sampling years with varying rainfall patterns. A significant $(P<0.05)$ difference in total abundance, taxa richness and Shannon index among dune microhabitats was found only in certain season time, particularly in 2013; however, no significant $(P>0.05)$ differences were found among dune microhabitats when averaged on three sampling seasons within the year of either 2012 or 2013. In all, the taxonomical structure differed considerably from the community structure in ground-active arthropod response to rainfall-induced dune microhabitats. The spatial distribution of taxonomical groups among dune microhabitats was significantly affected by inter-annual rainfall changes, whereas that of community structure was affected by both intra- and inter-annual rainfall changes in desertified ecosystems.
\end{abstract}

Keywords: ground-active arthropod; spatial distribution; desertified region; dune microhabitat; rainfall change

Citation: LIU Rentao, ZHU Fan, Yosef STEINBERGER. 2016. Ground-active arthropod responses to rainfall-induced dune microhabitats in a desertified steppe ecosystem, China. Journal of Arid Land, 8(4): 632-646. doi: $10.1007 / \mathrm{s} 40333-016-0008-9$

Sand dunes occur in many parts of the world including deserts and other semi-arid regions as well as along many coastlines (Breckle et al., 2008). The aspect, angle and orientation are typical characteristics of sand dune systems that determine the microhabitat differences along dune slope, in term of water availability, runoff generation, soil biological crusts and plant performances (Smettan et al., 1993; Pen-Mouratov et al., 2010). Climate changes, i.e. rainfall change can directly affect the distribution of soil water content and related biotic activities throughout runoff generation along dune slopes (Kidron, 1999). Heretofore, dune microhabitats receive more

\footnotetext{
*Corresponding author: LIU Rentao (E-mail: liubarilanu@gmail.com; liu_rt@nxu.edu.cn)

Received 2015-10-12; revised 2016-01-12; accepted 2016-01-20

(C) Xinjiang Institute of Ecology and Geography, Chinese Academy of Sciences, Science Press and Springer-Verlag Berlin Heidelberg 2016
} 
attention in relation to the bioprocess, stabilization and management of sand land under rainfall changes (Rozé and Lemauviel, 2004).

There were a great number of literatures concerning the changes of microhabitats including abiotic and biotic properties along sand dune slopes. Soil resources including soil moisture, organic carbon and total nitrogen contents were found redistributed in sampling site along dune slopes (Zuo et al., 2008). The occurrence of soil biological crusts depended on the settings along dune slopes which were supported by the application of a combination of topology plus physiological and soil parameters (Breckle et al., 2008). Zuo et al. (2008) suggested that plant distributions were determined by a combination of soil properties and topographic feature at mobile dune scale. Sabino et al. (1993) reported that the restoration of the original vegetation was a distinguished objective during the process of dune restoration. Sites consisting of different microhabitats were considered to support a large variety of plant species (Olff and Ritchie, 1998).

Under rainfall changes, it was reported that the runoff generation only occurred at the very bottom of the Nizzana sand dunes with a threshold of rainfall amount and intensity (Kidron and Yair, 1997). Both runoff and sediment yield would affect not only plant density and biomass, but also animal distribution along dune slope (Breckle et al., 2008). The micro-topography, soil and climate together were thought to exert strong influences on plant distribution at small scale (Maestre et al., 2003). The combination of soil (abiotic) and plant (biotic) properties along dune slope was an important factor in determining arthropod community (Canepuccia et al., 2009; Liu, 2012). However, few studies reveal a distribution pattern of ground-active arthropods along sand dune slopes with rainfall changes in arid ecosystems.

Ground-active arthropods exposed at the soil surface are found to be sensitive not only to the microhabitats along dune slope, but also to rainfall changes by means of dispersal ability (Thomas, 2000), habitat specialization and trophic level (Holt et al., 1999). Ground-active arthropods are ecologically important in many aspects: (1) they can act as pollinators and important components of food chains and nutrient cycles; (2) they can alter soil structure and fertility in arid and semi-arid regions (Lavelle and Spain, 2001); and (3) the biotic interactions in soil can regulate the structure and function of aboveground communities (Wardle et al., 2004). It was reported that rainfall pattern had direct impacts on specialized components of local communities such as herbivory and pollination and altered ecological patterns such as biodiversity and community composition (Canepuccia et al., 2008, 2009). Therefore, any changes in the environmental conditions under rainfall changes would affect the spatial distribution of ground-active arthropods along dune slopes (Doblas-Miranda et al., 2009). However, the spatial distribution of ground-active arthropods along dune slopes remained unclear at time scales with rainfall changes in desertified steppe ecosystems.

The aim of this study was to (1) investigate the spatial distribution of ground-active arthropods among dune microsites (i.e. top, midslope and bottom); (2) compare the effect of sampling time differences with rainfall changes on spatial distribution of ground-active arthropods among dune microhabitats; and (3) probe into the contribution of abiotic and biotic conditions to the distribution of ground-active arthropods with sampling timing. We hypothesized that (1) there was a similar distribution of ground-arthropods within dune microhabitats between sampling timing; (2) dune bottom could enhance taxonomical richness and diversity in comparison to the other dune microhabitats. Information about arthropod responses to dune microhabitats and rainfall pattern in environmental contexts was needed to gain a more-comprehensive understanding of the ecological consequences of dune microhabitats on organization structure of arthropod communities in desertified regions.

\section{Materials and methods}

\subsection{Study area}

The study was conducted in northeastern Yanchi county $\left(37^{\circ} 04^{\prime}-38^{\circ} 10^{\prime} \mathrm{N}, 106^{\circ} 30^{\prime}-107^{\circ} 41^{\prime} \mathrm{E}\right.$; $1,400 \mathrm{~m}$ asl), located at the southwestern fringe of $\mathrm{Mu}$ Us Sandy Land in the Ningxia Hui 
autonomous region of China. The region has a temperate continental semi-arid monsoonal climate with mean multi-annual precipitation of $250-300 \mathrm{~mm}$. Almost $70 \%$ of the total precipitation occurs between June and September. Mean annual potential pan-evaporation is 2,710 $\mathrm{mm}$. Annual mean temperature is $8^{\circ} \mathrm{C}-9^{\circ} \mathrm{C}$, with the lowest and highest monthly mean temperatures of $-8.7^{\circ} \mathrm{C}$ in January and $22.9^{\circ} \mathrm{C}$ in July, respectively.

In the study sites, the landscape is characterized by several dunes and large-area interdune lowlands. Under naturally restored area by fenced exclosure, most mobile sand dunes were stabilized with improved soil properties such as soil texture, organic carbon and water availability, soil crusts and plant performances (Han et al., 2014). The dunes are up to 4-9 $\mathrm{m}$ high, with a dune angle of $15^{\circ}-25^{\circ}$. The main soil types are Arthi-sandic Entisols (i.e. sandy soil) (Spaargaren and Deckers, 1998). The growing season is from April to September. The vegetation component mainly includes the annuals (i.e. Salsola collina, Corispermum hyssopifolium and Artimesia scoparia), perennials (i.e. Pennisetum centrasiaticum, Aneurolepidium dasystachys and Cleistogenes gracilis), shrub (i.e. Helianthemum scoparium and Caragana koushinskii) and subshrub (A. ordosica and Lespedeza potaninii).

\subsection{Experimental design}

The research was carried out in spring (i.e. early May), summer (i.e. late July) and autumn (i.e. late September) from 2012 to 2013. Five dunes of 30-50 m apart from each other were chosen as replicates with almost similar topography $\left(15^{\circ}-20^{\circ}\right)$, height $(4-6 \mathrm{~m})$ and size (ca. $\left.35 \mathrm{~m} \times 40 \mathrm{~m}\right)$. In each dune, three plots (i.e. microhabitat) from dune top through midslope to bottom were established. In each plot, four sampling points of 5-m interval were set along northwest, southwest, southeast and northeast, respectively, giving a total of 60 sampling points (i.e. 4 sampling points $\times 3$ plots (dune slop) $\times 5$ replicate dunes) for each season. The distances from dune top throughout midslope to bottom were 15-m and 10-m intervals, respectively.

\subsection{Arthropod samples and identification}

At each sampling point, a pitfall trap (7-cm in diameter, $10-\mathrm{cm}$ in depth) was placed with the opening of the trap level on the soil surface. The pitfall traps were filled with approximately 70 $\mathrm{mL}$ of $70 \%$ ethanol solution, and left at the study sites for 10 consecutive days (day and night). Traps were checked every three days during the sampling period, and fresh ethanol solution was added as needed. All arthropod specimens obtained during the study periods were stored in $75 \%$ alcohol. We identified these specimens to the order and family levels by using the classification of Zheng and Gui (2004) and Yin (2001), based on their morphological features as observed under a binocular microscope $(40 \times)$.

\subsection{Abiotic and biotic environmental measurement}

The climatic data (air temperature and precipitation) were collected for each month from an adjacent meteorological station (i.e. Ningxia Meteorological Bureau). At each sampling point during each sampling period, a quadrat of $50 \mathrm{~cm} \times 50 \mathrm{~cm}$ area was sampled for the determination of herbaceous community characteristics for each of the three plots. The herbaceous vegetation indices included: (1) species richness (SR); (2) plant density (PD, individuals $/ \mathrm{m}^{2}$ ) and (3) plant height $(\mathrm{PH}, \mathrm{cm})$.

Meantime, a composite soil sample at each sampling point was collected by using a $5-\mathrm{cm}$ diameter soil auger, and was sieved through a 2-mm sieve for removing organic debris and stones. The particle-size distribution, i.e. coarse sand content (CS, $>0.25 \mathrm{~mm}$ ), fine sand content (FS, $0.05-0.25 \mathrm{~mm})$ and clay plus silt content $(\mathrm{C}+\mathrm{S},<0.05 \mathrm{~mm})$, was determined by the pipette method in a sedimentation cylinder by using sodium hexametaphosphate as the dispersing agent (ISSCAS, 1978). Soil organic carbon was measured using the $\mathrm{K}_{2} \mathrm{Cr}_{2} \mathrm{O}_{7}-\mathrm{H}_{2} \mathrm{SO}_{4}$ oxidation method of Walkey and Black, and soil total nitrogen followed the Kjeldahl procedure (UDK 140 Automatic Steam Distilling Unit, Automatic Titroline 96, Italy). Soil temperature (ST) and soil moisture (SM) at the depth of $0-10 \mathrm{~cm}$ was determined by using a portable thermometer (Sato Keiryoki Mfg. Co. Ltd., Tokyo, Japan) and by drying the soil samples at $105^{\circ} \mathrm{C}$ for $48 \mathrm{~h}$, respectively. 


\subsection{Statistical analysis}

The data obtained from the four sample points within each slope microsite were pooled together in order to ensure the statistical analysis. Then, the arthropod community was expressed as: (1) the abundance of each taxonomic group (individuals/trap); (2) the group richness (number of taxonomic group/trap); and (3) the diversity by using Shannon's index. Taxa together that were present in less than two individuals were excluded in order to avoid the results being disproportionately affected by rare groups (Staley et al., 2007).

Descriptive statistics and significance tests on the raw data were conducted using SPSS 15.0 software for Windows (SPSS Inc., Chicago, Illinois, USA). One-way ANOVA and Tukey's (HSD) post hoc tests were used to determine differences in all the measured variables (abiotic and biotic) in each separate season and averaged over the three sampling periods within a year. Before applying parametric tests, we tested for normality and homogeneity of variances. For all tests, statistically significant differences were assigned at $P<0.05$.

Ordination techniques were used to determine the relative contribution of the measured environmental variables to the community composition (Lepš and Šmilauer, 2003). The taxa abundance data in 2012 and 2013 were first separately analyzed by detrended correspondence analysis (DCA) to decide the response models (linear or unimodal) for arthropod community data. The value of the first DCA ordination axis was $<4$ for taxonomic group data in 2012 and 2013, suggesting that redundancy analysis (RDA) was an appropriate approach. DCA and RDA were carried out using CANOCO software for Windows 4.5 (Microcomputer Power, Ithaca, USA).

Before RDA, a Hellinger transformation was applied to remove the issue of double-zeros in the data matrix and improve the analysis. The data and Monte Carlo reduced model tests with 499 unrestricted permutations were used to statistically evaluate the significance of the first canonical axis and of all canonical axes combined. In order to meet the requirements of the Monte Carlo reduced model test, we log-transformed the taxonomic group data.

The relative contribution of each environmental variable to the explained variation in the data from each year was determined by the inertia from the conditional (or partial) effects, which show the amount of additional variation each variable contributes when it is added to the model (Lepš and Šmilauer, 2003). Partial RDA and the Monte Carlo permutation test were used to determine the conditional effect of soil temperature, soil moisture, coarse sand content, herbaceous density and herbaceous height, etc. with the remaining variables as covariables.

\section{Results}

\subsection{Environmental variables}

Mean annual precipitation and annual mean air temperature was $292 \mathrm{~mm}$ and $8.6^{\circ} \mathrm{C}$ during 38 years (i.e. 1975-2013), respectively (Fig. 1). The annual precipitation and mean temperature were $308 \mathrm{~mm}$ and $8.1^{\circ} \mathrm{C}$ in 2012 , and $291.5 \mathrm{~mm}$ and $9.4^{\circ} \mathrm{C}$ in 2013 , respectively. However, the coefficient of variations (CVs) for precipitation were 1.02, 1.05, 1.40 for 38 years (1975-2013), 2012 and 2013, respectively. Namely, precipitation distribution was similar whereas total precipitation amount was a little higher in 2012 relative to the multi-annual (i.e. 38 years) mean value. Total precipitation amount was similar whereas precipitation distribution differed much in 2013 relative to the annual mean value. In 2013, a dry spring (from March to May) was found with total rainfall amount of only $21.3 \mathrm{~mm}$ (half of multi-annual mean value), whereas a wet summer was found with rainfall amount of $106.5 \mathrm{~mm}$ in July. The mean temperature was a little lower in 2012, whereas rather higher in 2013 than that of the multi-annual mean value (Fig. 1).

Soil moisture content averaged over the three sampling periods was significantly affected by dune slopes in 2012 and 2013 (Table 1). Soil moisture content increased markedly $(P<0.05)$ from dune top throughout midslope to dune bottom, particularly in $2013(P<0.0001)$. A reverse pattern was followed by soil temperature averaged over the three sampling periods $(P<0.001)$. In 2012 and 2013, soil temperature markedly decreased $(P<0.001)$ from dune top throughout midslope to 
bottom. Soil coarse sand contents markedly decreased $(P<0.01)$ from dune top throughout midslope to bottom in 2013. However, soil clay plus silt contents markedly increased $(P<0.01)$ from dune top and midslope to dune bottom in both years. A similar pattern was found in soil organic carbon and total nitrogen contents, with markedly $(P<0.05)$ higher values at dune bottom than at dune top. From 2012 to 2013, soil moisture content markedly increased $(P<0.05)$ only at dune bottom, whereas soil clay plus silt contents considerably increased for all three dune microhabitats (i.e. dune top, midslope, dune bottom).

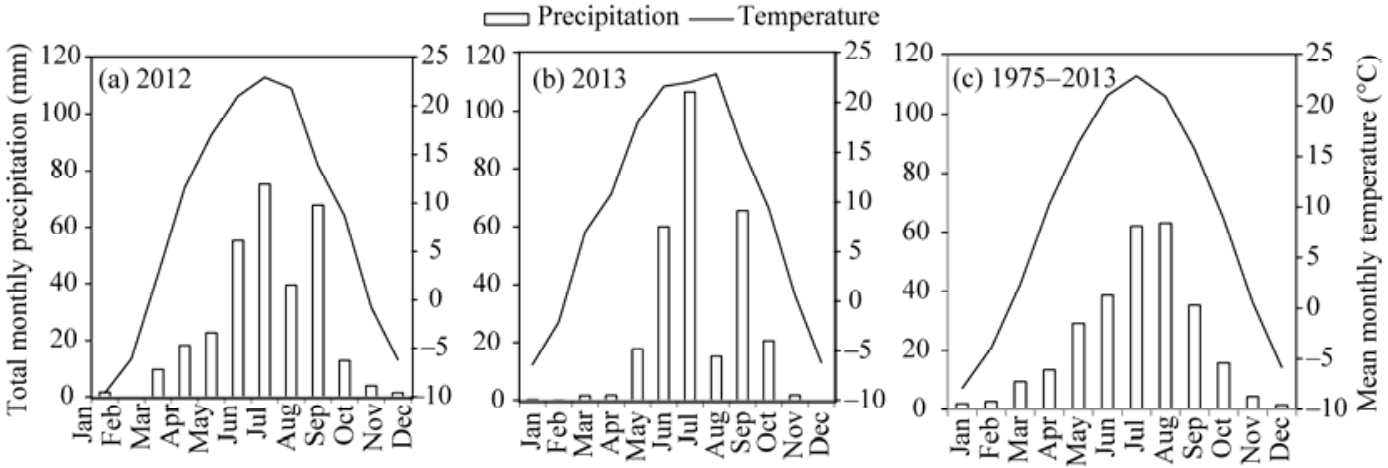

Fig. 1 Air temperature and precipitation at the experimental site

Herbaceous density and height were unaffected $(P>0.05)$ by dune slope in both years, whereas herbaceous species richness was significantly affected $(P<0.05)$ only in 2012 (Table 1). Herbaceous species richness was significantly $(P<0.05)$ higher at dune bottom than at dune top, with an intermediate value at dune midslope. From 2012 to 2013, herbaceous density and species richness considerably decreased for all three dune microhabitats.

Table 1 Soil properties and herbaceous community indices averaged three sampling timings with different dune microhabitats in 2012 and 2013

\begin{tabular}{|c|c|c|c|c|c|c|}
\hline \multirow{2}{*}{ Item } & \multicolumn{3}{|c|}{2012} & \multicolumn{3}{|c|}{2013} \\
\hline & Dune top & Dune midslope & Dune bottom & Dune top & Dune midslope & Dune bottom \\
\hline $\mathrm{SM}\left({ }^{\circ} \mathrm{C}\right)$ & $1.3 \pm 0.1^{\mathrm{b}}$ & $1.7 \pm 0.2^{\mathrm{ab}}$ & $1.8 \pm 0.1^{\mathrm{a}}$ & $1.0 \pm 0.1^{\mathrm{c}}$ & $1.5 \pm 0.0^{\mathrm{b}}$ & $2.7 \pm 0.2^{\mathrm{a}}$ \\
\hline ST (\%) & $20.4 \pm 0.0^{\mathrm{a}}$ & $20.0 \pm 0.0^{\mathrm{b}}$ & $19.8 \pm 0.0^{\mathrm{c}}$ & $20.4 \pm 0.0^{\mathrm{a}}$ & $20.1 \pm 0.0^{\mathrm{b}}$ & $19.9 \pm 0.0^{c}$ \\
\hline CS $(\%)$ & $21.1 \pm 1.3^{\mathrm{a}}$ & $20.1 \pm 1.8^{\mathrm{a}}$ & $18.5 \pm 0.8^{\mathrm{a}}$ & $24.1 \pm 1.0^{\mathrm{a}}$ & $19.2 \pm 0.8^{\mathrm{b}}$ & $19.0 \pm 1.4^{\mathrm{b}}$ \\
\hline FS (\%) & $74.2 \pm 1.5^{\mathrm{a}}$ & $76.4 \pm 1.5^{\mathrm{a}}$ & $75.2 \pm 0.9^{\mathrm{a}}$ & $70.3 \pm 1.5^{\mathrm{a}}$ & $73.9 \pm 1.1^{\mathrm{a}}$ & $72.1 \pm 1.2^{\mathrm{a}}$ \\
\hline $\mathrm{C}+\mathrm{S}(\%)$ & $4.7 \pm 0.3^{b}$ & $3.5 \pm 0.5^{b}$ & $6.3 \pm 0.6^{\mathrm{a}}$ & $5.6 \pm 0.6^{\mathrm{b}}$ & $6.9 \pm 0.6^{\mathrm{b}}$ & $8.9 \pm 0.5^{\mathrm{a}}$ \\
\hline TN (\%) & $0.2 \pm 0.0^{\mathrm{b}}$ & $0.2 \pm 0.0^{\mathrm{b}}$ & $0.3 \pm 0.0^{\mathrm{a}}$ & $0.2 \pm 0.0^{\mathrm{b}}$ & $0.2 \pm 0.0^{\mathrm{ab}}$ & $0.2 \pm 0.0^{\mathrm{a}}$ \\
\hline SOC (\%) & $1.4 \pm 0.3^{b}$ & $1.9 \pm 0.2^{\mathrm{b}}$ & $2.6 \pm 0.2^{\mathrm{a}}$ & $1.5 \pm 0.1^{\mathrm{b}}$ & $1.9 \pm 0.1^{\mathrm{a}}$ & $2.1 \pm 0.1^{\mathrm{a}}$ \\
\hline $\mathrm{PD}\left(\right.$ number $\left./ \mathrm{m}^{2}\right)$ & $415.0 \pm 82.7^{\mathrm{a}}$ & $366.6 \pm 52.7^{\mathrm{a}}$ & $264.9 \pm 28.2^{\mathrm{a}}$ & $93.5 \pm 7.5^{\mathrm{a}}$ & $109.9 \pm 13.4^{\mathrm{a}}$ & $84.6 \pm 15.3^{\mathrm{a}}$ \\
\hline $\mathrm{PH}(\mathrm{cm})$ & $15.3 \pm 5.4^{\mathrm{a}}$ & $11.5 \pm 0.7^{\mathrm{a}}$ & $11.8 \pm 1.1^{\mathrm{a}}$ & $10.8 \pm 1.3^{\mathrm{a}}$ & $14.3 \pm 1.7^{\mathrm{a}}$ & $13.0 \pm 0.9^{\mathrm{a}}$ \\
\hline SR & $7.6 \pm 0.2^{\mathrm{b}}$ & $8.3 \pm 0.4^{\mathrm{ab}}$ & $9.2 \pm 0.5^{\mathrm{a}}$ & $8.3 \pm 0.8^{\mathrm{a}}$ & $8.7 \pm 1.3^{\mathrm{a}}$ & $10.1 \pm 0.9^{\mathrm{a}}$ \\
\hline
\end{tabular}

Note: Different letters mean significant differences at $P<0.05$ level among three microhabitats in 2012 and 2013. SM, soil moisture; ST, soil temperature; $\mathrm{CS}$, coarse sand content; FS, fine sand content; $\mathrm{C}+\mathrm{S}$, clay plus silt content; $\mathrm{TN}$, total nitrogen content; SOC, soil organic carbon; PD, plant density; PH, plant height; SR, species richness. Mean \pm SE.

\subsection{Taxonomical composition and their abundances}

A total of 42 taxonomic groups from 12 orders and 37 families plus additional five larval groups of ground-active arthropods were collected in the study sites during all the sampling periods (Table 2). The overall ground-active arthropod assemblage was found to be dominated in terms of abundance by the Melolonthidae family (Coleoptera, 41.16\%) in addition to subdominant Carabidae, Glaphyridae and Tenebrionidae families (Coleoptera, 8.12\%, 9.18\% and 8.67\%, respectively) and Formicidae family (Hymenoptera, 11.39\%). These five families together comprised $78.52 \%$ of the total number of individuals of ground-active arthropods. Another six 
Table 2 The abundance of taxonomical groups averaged three sampling timing within the year among dune microhabitats

\begin{tabular}{|c|c|c|c|c|c|c|c|c|}
\hline \multirow{2}{*}{ Taxa } & $\mathrm{T}$ & M & B & & $\mathrm{T}$ & M & $\mathrm{B}$ & \multirow{2}{*}{$F$} \\
\hline & \multicolumn{3}{|c|}{2012 (number/trap) } & & \multicolumn{3}{|c|}{2013 (number/trap) } & \\
\hline Scutigeridae & $0.00 \pm 0.00$ & $0.00 \pm 0.00$ & $0.00 \pm 0.00$ & - & $0.13 \pm 0.13$ & $0.07 \pm 0.07$ & $0.27 \pm 0.16$ & $0.64^{\mathrm{ns}}$ \\
\hline Phalangiidae & $0.00 \pm 0.00$ & $0.13 \pm 0.13$ & $0.20 \pm 0.08$ & $1.27^{\mathrm{ns}}$ & $0.07 \pm 0.07$ & $0.13 \pm 0.08$ & $0.00 \pm 0.00$ & $1.20^{\mathrm{ns}}$ \\
\hline Theridiidae & $0.07 \pm 0.07$ & $0.20 \pm 0.07$ & $0.07 \pm 0.13$ & $0.67^{\mathrm{ns}}$ & $0.00 \pm 0.00$ & $0.00 \pm 0.00$ & $0.00 \pm 0.00$ & - \\
\hline Thomisidae & $1.00 \pm 0.24$ & $0.27 \pm 0.16$ & $0.27 \pm 0.12$ & $5.50^{*}$ & $0.13 \pm 0.08$ & $0.73 \pm 0.12$ & $0.33 \pm 0.11$ & $8.40^{* *}$ \\
\hline Salticidae & $0.07 \pm 0.07$ & $0.07 \pm 0.00$ & $0.00 \pm 0.00$ & $0.50^{\mathrm{ns}}$ & $0.07 \pm 0.07$ & $0.00 \pm 0.00$ & $0.00 \pm 0.00$ & $1.00^{\mathrm{ns}}$ \\
\hline Lycosidae & $0.20 \pm 0.13$ & $0.13 \pm 0.21$ & $0.33 \pm 0.08$ & $0.45^{\mathrm{ns}}$ & $0.27 \pm 0.12$ & $0.60 \pm 0.19$ & $0.40 \pm 0.27$ & $0.68^{\text {ns }}$ \\
\hline Liocranidae & $0.00 \pm 0.00$ & $0.13 \pm 0.00$ & $0.00 \pm 0.00$ & $1.00^{\mathrm{ns}}$ & $0.07 \pm 0.07$ & $0.33 \pm 0.18$ & $0.20 \pm 0.13$ & $0.96^{\mathrm{ns}}$ \\
\hline Philodromidae & $0.33 \pm 0.15$ & $0.33 \pm 0.11$ & $0.33 \pm 0.15$ & $0.00^{\mathrm{ns}}$ & $0.33 \pm 0.18$ & $0.27 \pm 0.12$ & $0.20 \pm 0.13$ & $0.20^{\mathrm{ns}}$ \\
\hline Gnaphosidae & $0.00 \pm 0.00$ & $0.00 \pm 0.00$ & $0.00 \pm 0.00$ & - & $0.07 \pm 0.07$ & $0.33 \pm 0.11$ & $0.20 \pm 0.13$ & $1.60^{\text {ns }}$ \\
\hline Scutelleridae & $0.60 \pm 0.37$ & $0.93 \pm 0.55$ & $1.20 \pm 0.29$ & $0.51^{\mathrm{ns}}$ & $1.20 \pm 0.71$ & $0.47 \pm 0.23$ & $1.33 \pm 0.33$ & $0.98^{\mathrm{ns}}$ \\
\hline Coreidae & $2.40 \pm 0.82$ & $2.07 \pm 0.31$ & $1.73 \pm 0.37$ & $0.37^{\mathrm{ns}}$ & $1.60 \pm 0.39$ & $2.07 \pm 0.44$ & $3.27 \pm 2.06$ & $0.49^{\text {ns }}$ \\
\hline Alydidae & $0.00 \pm 0.00$ & $0.07 \pm 0.13$ & $0.13 \pm 0.07$ & $0.60^{\mathrm{ns}}$ & $0.27 \pm 0.07$ & $0.07 \pm 0.07$ & $0.33 \pm 0.15$ & $1.86^{\mathrm{ns}}$ \\
\hline Lygaeidae & $0.40 \pm 0.12$ & $0.47 \pm 0.11$ & $0.33 \pm 0.20$ & $0.20^{\mathrm{ns}}$ & $0.93 \pm 0.19$ & $0.60 \pm 0.32$ & $2.27 \pm 1.41$ & $1.10^{\mathrm{ns}}$ \\
\hline Miridae & $0.13 \pm 0.08$ & $0.07 \pm 0.40$ & $0.60 \pm 0.07$ & $1.48^{\mathrm{ns}}$ & $0.00 \pm 0.00$ & $0.07 \pm 0.07$ & $0.13 \pm 0.13$ & $0.60^{\text {ns }}$ \\
\hline Gryllotalpidae & $0.00 \pm 0.00$ & $0.00 \pm 0.00$ & $0.00 \pm 0.00$ & - & $0.20 \pm 0.13$ & $0.07 \pm 0.07$ & $0.07 \pm 0.07$ & $0.67^{\mathrm{ns}}$ \\
\hline Tettigoniidae & $0.73 \pm 0.41$ & $0.33 \pm 0.07$ & $0.07 \pm 0.15$ & $1.71^{\mathrm{ns}}$ & $0.00 \pm 0.00$ & $0.00 \pm 0.00$ & $0.00 \pm 0.00$ & - \\
\hline Catantopidae & $0.27 \pm 0.12$ & $0.27 \pm 0.07$ & $0.07 \pm 0.19$ & $0.69^{\text {ns }}$ & $0.07 \pm 0.07$ & $0.07 \pm 0.07$ & $0.00 \pm 0.00$ & $0.50^{\mathrm{ns}}$ \\
\hline Acrididae & $0.00 \pm 0.00$ & $0.20 \pm 0.00$ & $0.00 \pm 0.00$ & $6.00^{*}$ & $0.00 \pm 0.00$ & $0.00 \pm 0.00$ & $0.00 \pm 0.00$ & - \\
\hline Cicadellidae & $1.53 \pm 0.48$ & $0.47 \pm 0.12$ & $0.27 \pm 0.08$ & $5.54^{*}$ & $0.00 \pm 0.00$ & $0.00 \pm 0.00$ & $0.00 \pm 0.00$ & - \\
\hline Pemphigidae & $0.33 \pm 0.18$ & $0.20 \pm 0.27$ & $0.40 \pm 0.13$ & $0.25^{\mathrm{ns}}$ & $0.00 \pm 0.00$ & $0.00 \pm 0.00$ & $0.00 \pm 0.00$ & - \\
\hline Labiduridae & $0.00 \pm 0.00$ & $0.20 \pm 0.12$ & $0.40 \pm 0.13$ & $3.60^{*}$ & $5.40 \pm 1.72$ & $6.27 \pm 0.83$ & $1.87 \pm 0.45$ & $4.22^{*}$ \\
\hline Adult Carabidae & $6.00 \pm 1.05$ & $14.53 \pm 2.74$ & $7.53 \pm 2.88$ & $3.68^{*}$ & $1.20 \pm 0.45$ & $5.07 \pm 0.76$ & $2.00 \pm 0.58$ & $11.25^{* *}$ \\
\hline Adult Melolonthidae & $8.00 \pm 1.62$ & $10.80 \pm 2.42$ & $14.67 \pm 0.34$ & $3.91^{*}$ & $44.60 \pm 6.78$ & $47.60 \pm 13.53$ & $58.47 \pm 8.28$ & $0.54^{\mathrm{ns}}$ \\
\hline Adult Glaphyridae & $0.80 \pm 0.23$ & $2.07 \pm 0.40$ & $2.40 \pm 1.26$ & $1.19^{\mathrm{ns}}$ & $7.60 \pm 0.53$ & $7.33 \pm 1.87$ & $20.87 \pm 2.31$ & $19.64^{* * *}$ \\
\hline Adult Histeridae & $0.00 \pm 0.00$ & $0.07 \pm 0.00$ & $0.00 \pm 0.00$ & $1.00^{\mathrm{ns}}$ & $0.20 \pm 0.13$ & $1.87 \pm 1.78$ & $0.13 \pm 0.08$ & $0.90^{\mathrm{ns}}$ \\
\hline Adult Scarabaeidae & $0.13 \pm 0.13$ & $0.27 \pm 0.00$ & $0.00 \pm 0.00$ & $1.20^{\mathrm{ns}}$ & $0.07 \pm 0.07$ & $0.13 \pm 0.08$ & $0.00 \pm 0.00$ & $1.20^{\mathrm{ns}}$ \\
\hline Adult Chrysomelidae & $0.20 \pm 0.08$ & $0.27 \pm 0.07$ & $0.07 \pm 0.12$ & $1.17^{\mathrm{ns}}$ & $0.20 \pm 0.13$ & $0.13 \pm 0.08$ & $0.00 \pm 0.00$ & $1.27^{\mathrm{ns}}$ \\
\hline Adult Buprestidae & $2.87 \pm 0.60$ & $2.13 \pm 0.40$ & $1.73 \pm 0.69$ & $1.00^{\mathrm{ns}}$ & $1.20 \pm 0.17$ & $1.13 \pm 0.27$ & $1.00 \pm 0.11$ & $0.27^{\mathrm{ns}}$ \\
\hline Adult Elateridae & $0.00 \pm 0.00$ & $0.00 \pm 0.00$ & $0.00 \pm 0.00$ & - & $0.20 \pm 0.13$ & $0.07 \pm 0.07$ & $0.07 \pm 0.07$ & $0.67^{\mathrm{ns}}$ \\
\hline Adult Silphidae & $0.53 \pm 0.31$ & $0.00 \pm 0.00$ & $0.07 \pm 0.00$ & $2.53^{\mathrm{ns}}$ & $0.07 \pm 0.07$ & $0.00 \pm 0.00$ & $0.00 \pm 0.00$ & $1.00^{\mathrm{ns}}$ \\
\hline Adult Teneberionidae & $10.73 \pm 1.24$ & $10.87 \pm 1.21$ & $4.33 \pm 1.54$ & $7.78^{* *}$ & $5.60 \pm 0.64$ & $4.27 \pm 0.37$ & $3.00 \pm 0.32$ & $7.76^{* *}$ \\
\hline Adult Curculionidae & $3.27 \pm 0.89$ & $2.93 \pm 0.29$ & $1.80 \pm 0.51$ & $1.56^{\mathrm{ns}}$ & $3.93 \pm 0.31$ & $4.07 \pm 0.52$ & $4.27 \pm 0.88$ & $0.07^{\mathrm{ns}}$ \\
\hline Larval Carabidae & $0.00 \pm 0.00$ & $0.00 \pm 0.00$ & $0.00 \pm 0.00$ & - & $0.00 \pm 0.00$ & $2.00 \pm 0.57$ & $0.60 \pm 0.31$ & $7.60^{* *}$ \\
\hline Larval Coccinellidae & $0.00 \pm 0.00$ & $0.00 \pm 0.00$ & $0.00 \pm 0.00$ & - & $0.00 \pm 0.00$ & $0.00 \pm 0.00$ & $0.33 \pm 0.15$ & $5.00^{*}$ \\
\hline Larval Teneberionidae & $0.00 \pm 0.00$ & $0.13 \pm 0.07$ & $0.00 \pm 0.00$ & $2.67^{\mathrm{ns}}$ & $0.13 \pm 0.08$ & $0.00 \pm 0.00$ & $0.13 \pm 0.08$ & $1.33^{\mathrm{ns}}$ \\
\hline Larval Curculionidae & $0.00 \pm 0.00$ & $0.13 \pm 0.07$ & $0.07 \pm 0.13$ & $0.60^{\mathrm{ns}}$ & $0.00 \pm 0.00$ & $0.00 \pm 0.00$ & $0.07 \pm 0.07$ & $1.00^{\mathrm{ns}}$ \\
\hline Aslidae & $0.00 \pm 0.00$ & $0.00 \pm 0.00$ & $0.00 \pm 0.00$ & - & $0.27 \pm 0.12$ & $0.00 \pm 0.00$ & $0.00 \pm 0.00$ & $4.57^{*}$ \\
\hline Larval Lepidiptera & $0.33 \pm 0.18$ & $0.27 \pm 0.00$ & $0.00 \pm 0.00$ & $2.47^{\mathrm{ns}}$ & $0.33 \pm 0.21$ & $0.27 \pm 0.12$ & $0.27 \pm 0.19$ & $0.05^{\mathrm{ns}}$ \\
\hline Formicidae & $22.47 \pm 4.83$ & $7.07 \pm 1.79$ & $9.80 \pm 1.13$ & $7.29^{* *}$ & $1.73 \pm 0.94$ & $4.00 \pm 1.21$ & $5.87 \pm 1.00$ & $3.84^{*}$ \\
\hline Sphecidae & $0.00 \pm 0.00$ & $0.07 \pm 0.07$ & $0.07 \pm 0.07$ & $0.50^{\mathrm{ns}}$ & $0.00 \pm 0.00$ & $0.07 \pm 0.07$ & $0.00 \pm 0.00$ & $1.00^{\mathrm{ns}}$ \\
\hline Apidae & $0.00 \pm 0.00$ & $0.13 \pm 0.07$ & $0.07 \pm 0.13$ & $0.60^{\mathrm{ns}}$ & $0.13 \pm 0.13$ & $0.00 \pm 0.00$ & $0.00 \pm 0.00$ & $1.00^{\mathrm{ns}}$ \\
\hline Collembola & $0.07 \pm 0.07$ & $0.07 \pm 0.20$ & $0.20 \pm 0.07$ & $0.36^{\mathrm{ns}}$ & $0.00 \pm 0.00$ & $0.00 \pm 0.00$ & $0.00 \pm 0.00$ & - \\
\hline
\end{tabular}

Note: ${ }^{*}$ and ${ }^{* *}$ mean significance at $P<0.05$ and $P<0.01$ levels, respectively. "-" means no value and ${ }^{\text {ns }}$ means no significant differences.

$\mathrm{T}$, dune top; M, dune midslope; B, dune bottom. Mean \pm SE. 
taxonomical groups had the number of individuals ranging from $1.00 \%$ to $4.53 \%$ of the totals. However, the other 31 taxonomical groups made up only $6.64 \%$ of the totals, with each group comprising $<1 \%$ of the total number of individuals.

The composition and abundant distribution of dominant groups among dune microhabitats were similar between seasonal timings within the current-year, however, there was a marked change in the distribution pattern from 2012 to 2013 (Fig. 2; Table 2). In 2012, the dominant groups included the Melolonthidae, Carabidae and Tenebrionidae families (Coleoptera, 19.57\%, 16.41\% and $15.16 \%$, respectively) and Formicidae family (Hymenoptera, 23.01\%). The abundance of Carabidae family averaged over the three sampling seasons was significantly $(P<0.05)$ higher at dune midslope than at dune top (Fig. 2a). The abundance of Tenebrionidae family averaged over the three sampling seasons was significantly $(P<0.01)$ higher at dune midslope and top than at dune bottom (Fig. 2d). The abundance of Formicidae family averaged over the three sampling seasons was significantly $(P<0.01)$ higher at dune top than at dune midslope and bottom. The abundance of Melolonthidae family averaged over the three sampling seasons was significantly $(P<0.05)$ higher at dune bottom than at dune top.

In 2013, the dominant groups only included the Melolonthidae and Glaphyridae families (Coleoptera, $53.52 \%$, and $12.96 \%$, respectively). The abundance of Glaphyridae family was significantly $(P<0.001)$ higher at dune bottom than at dune top and midslope (Fig. 2e). However, the abundance of Melolonthidae family averaged over the three sampling seasons was unaffected $(P>0.05)$ by dune microhabitats (Fig. 2$)$.

\subsection{Community index of ground-active arthropods}

Total abundance, taxa richness and the Shannon index averaged over the three sampling seasons were found to be unaffected $(P>0.05)$ by dune microhabitats in either 2012 or 2013 (Fig. 3).

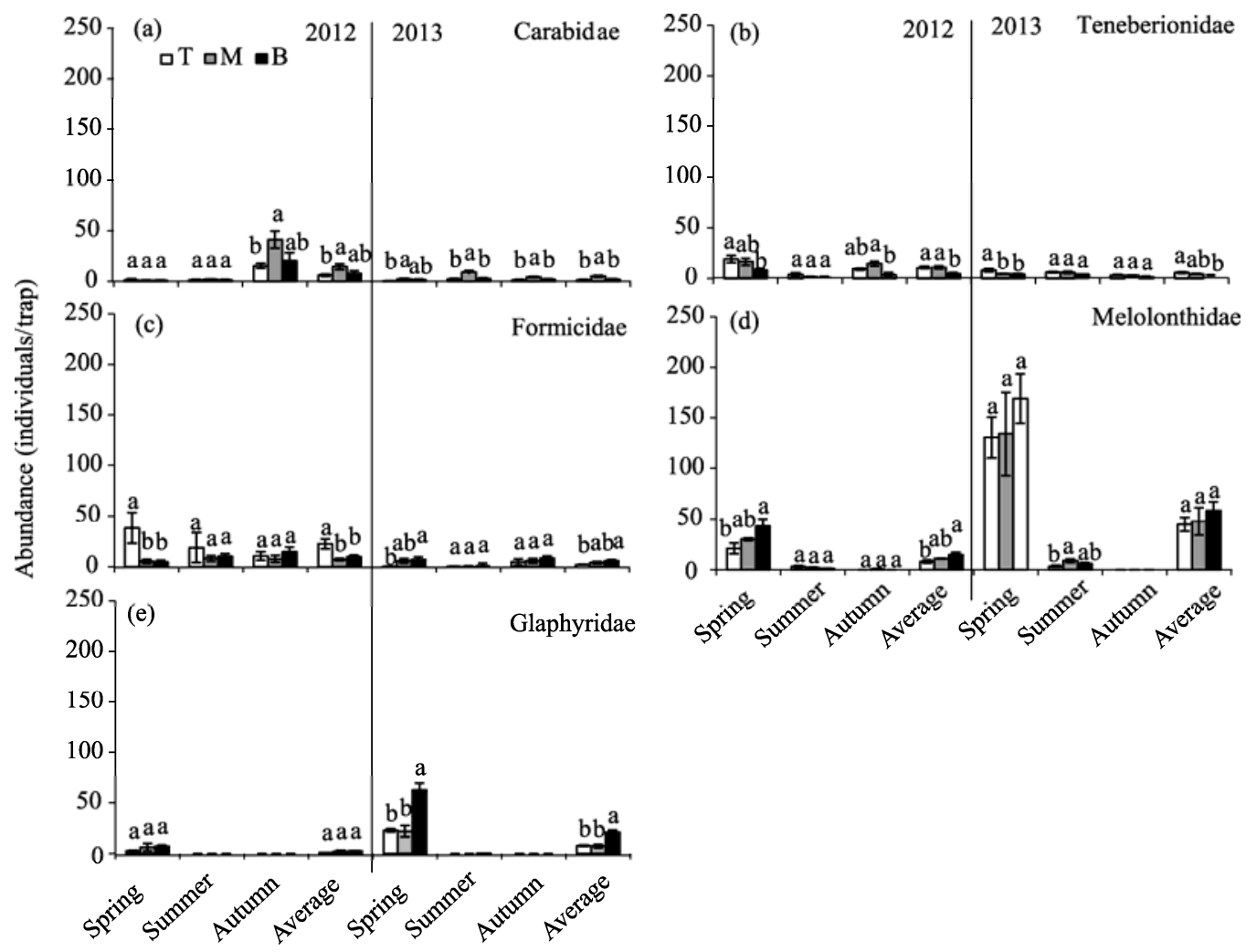

Fig. 2 Abundance distribution of dominant groups along the dune slopes in each sampling timing from 2012 to 2013. Different letters in the same sampling timing mean significant differences at $P<0.05$ level. T, dune top; M, dune midslope; B, dune bottom. 
However, in certain season time (only in 2013), a significant $(P<0.05)$ difference in total abundance, taxa richness and Shannon index was found among dune microhabitats. For example, in spring 2013, total abundance and taxa richness were markedly $(P<0.05)$ higher at dune bottom than at dune midslope and top. In summer, however, total abundance was markedly $(P<0.05)$ higher at dune midslope than at dune bottom, with the intermediate value at dune top. In autumn, total abundance, taxa richness and the Shannon index were all markedly $(P<0.05)$ higher at dune midslope than at both dune bottom and top.

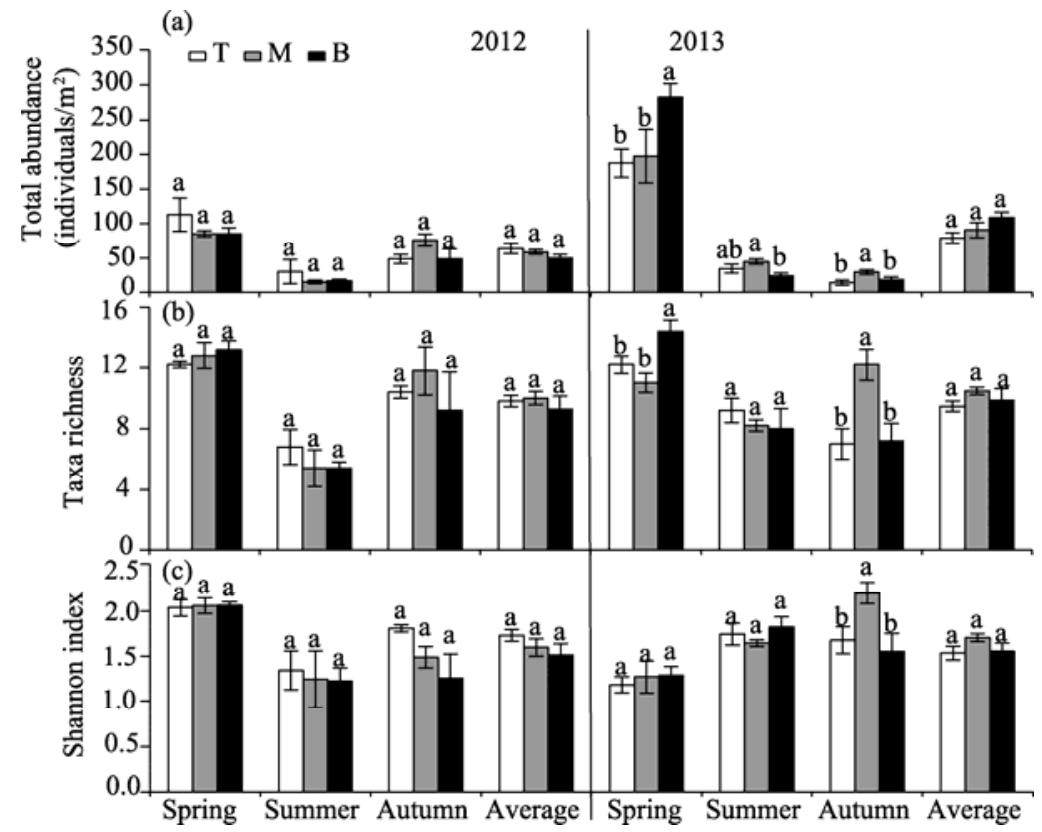

Fig. 3 Distribution of total abundance (a), taxa richness (b) and the Shannon index (c) along the dune slopes in each sampling timing from 2012 to 2013. Different letters in the same sampling timing mean significant differences at $P<0.05$ level. T, dune top; M, dune midslope; B, dune bottom.

\subsection{Contribution of environmental parameters to ground-active arthropods}

In 2012, separate RDA analysis (Fig. 4) showed that all the 10 environmental variables including soil properties (temperature, moisture, soil particle distribution, organic carbon and total nitrogen) and vegetation indices (herbaceous density, species richness and height) explained $71.9 \%$ of the total variation in the data, with axes 1 and 2 accounting for $24.9 \%$ and $18.3 \%$ of the total variation, respectively. Partial RDA showed that different environmental variables differed in their influences on the community composition of ground arthropods (Table 3). From all the ten environmental variables, only soil temperature $(P=0.002)$ and soil clay plus silt content $(P=0.03)$ were found to be significant under the Monte Carlo permutation test, whereas those of the remaining variables were not significant under the Monte Carlo permutation test (in all cases $P>0.05$ ). Soil temperature and soil clay plus silt content accounted for $20.0 \%$ and $11.0 \%$ of the total $100 \%$ variation explained by RDA, respectively, while the other variables that were not significant under the Monte Carlo permutation test accounted for the rest.

In 2013, separate RDA analysis (Fig. 4) showed that all the same 10 environmental variables explained $73.6 \%$ of the total variation in the data, with axes 1 and 2 accounting for $23.7 \%$ and $19.3 \%$ of the total variation, respectively. From all the ten environmental variables, only soil temperature $(P=0.016)$ and soil moisture $(P=0.028)$ were found to be significant under the Monte Carlo permutation test, whereas those of the remaining variables were not significant under the Monte Carlo permutation test (in all cases $P>0.05$ ) (Table 3 ). Soil temperature and soil moisture content accounted for $14.0 \%$ and $14.0 \%$ of the total $100 \%$ variation explained by RDA, respectively, while the other variables that were not significant under the Monte Carlo permutation test accounted for the rest. 

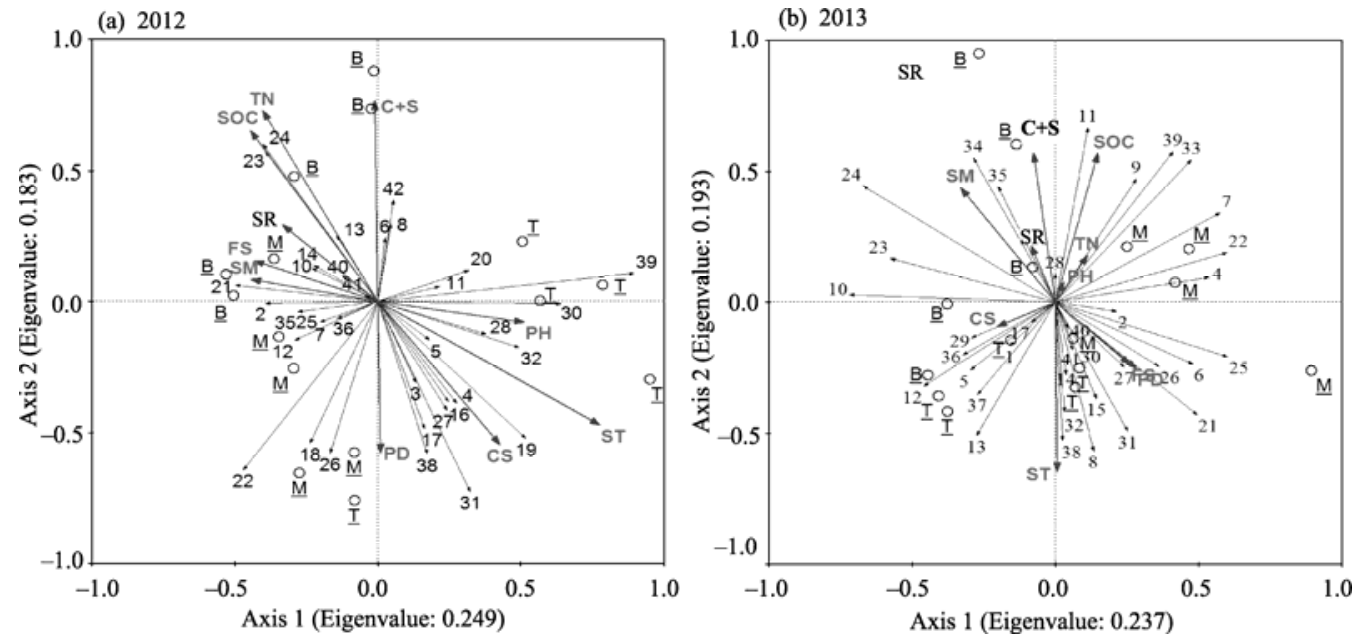

Fig. 4 Separate redundancy analysis plot of environmental contribution to ground-active arhtropod communities along dune slopes in 2012 (a; Monte Carlo test: Axis 1, $F=1.66, P=0.05$; All axis, $F=1.42, P=0.05$ ) and 2013 (b; All axis, $F=1.55, P=0.04)$. T, dune top; $\mathrm{M}$, dune midslope; $\mathrm{B}$, dune bottom. ST, soil temperature; SM, soil moisture; CS, coarse sand content; FS, fine sand content; $\mathrm{C}+\mathrm{S}$, clay plus silt content; SOC, soil organic carbon; $\mathrm{TN}$, total nitrogen; PD, plant density; PH, plant height; SR, species richness. The numbers mean the taxa: 1, Scutigeridae; 2, Phalangiidae; 3, Theridiidae; 4, Thomisidae; 5, Salticidae; 6, Lycosidae; 7, Liocranidae; 8, Philodromidae; 9, Gnaphosidae; 10, Scutelleridae; 11, Coreidae; 12, Alydidae; 13, Lygaeidae; 14, Miridae; 15, Gryllotalpidae; 16, Tettigoniidae; 17, Catantopidae; 18. Acrididae; 19, Cicadellidae; 20, Pemphigidae; 21, Labiduridae; 22, adult Carabidae; 23, adult Melolonthidae; 24, adult Glaphyridae, 25, adult Histeridae; 26, adult Scarabaeidae; 27, adult Chrysomelidae; 28, adult Buprestidae; 29, adult Elateridae; 30, adult Silphidae; 31, adult Teneberionidae; 32, adult Curculionidae; 33, larval Carabidae; 34, larval Coccinellidae; 35, larval Teneberionidae; 36, larval Curculionidae; 37, Aslidae; 38, larval Lepidiptera; 39, Formicidae; 40, Sphecidae; 41, Apidae; 42, Collembola.

\section{Discussion}

Different microsites (i.e. dune slope) were considered to support a large variety of plant species and soil resources (Olff and Ritchie, 1998; Zuo et al., 2008). In this study, soil moisture content markedly increased from dune top to bottom. A similar pattern was followed by soil organic carbon and total nitrogen contents, and soil clay plus silt content. These findings were in line with Sebastiá (2004). However, soil temperature decreased markedly from dune top to bottom. Topography influenced soil moisture, temperature and plant evapotranspiration, as well as the accumulation and export of nutrients and soil particles as indicated by Sebastiá (2004). It was suggested that the topography was heterogeneous in soil properties at a small scale as a result of differences in relative height, which conceded with the results by Zuo et al. $(2008,2010)$.

Herbaceous species richness was markedly higher at dune bottom in comparison to dune tope in year 2012, which agreed with the results from Horqin Sand Land according to Zuo et al. (2008). Plant spatial distribution in arid regions was reported to be strongly affected by small-scale variation in resources partitioning such as soil texture, moisture content and nutrient content (Puignaire et al., 1996; Pan et al., 1998). In 2012, the homogeneous rainfall distribution pattern (i.e. close to multi-annual rainfall distribution) and relatively great rainfall amount markedly harbored greater higher soil moisture content and soil nutrient at dune bottom than at dune midslope and top, which could facilitate seed germination, plant performances and growth, and the richness of seed bank (Zuo et al., 2012; Han et al., 2014). However, in 2013 the uneven rainfall distribution (i.e. especially with dry spring) could restrain seed germination and relevant plant performances along dune slope (Dijkstra et al., 2012; Song et al., 2014). No significant differences in herbaceous height, density and species richness were found along dune slopes, which was inconsistent with the result found in 2012 (Table 1) and in other sand dune 
Table 3 Separate redundancy analysis of the taxa abundance data in 2012 and 2013 for quantifying the conditional effects of the measured environmental variables on taxa composition using forward selection with Monte Carlo permutation test

\begin{tabular}{lcccc}
\hline Variables & Initial conditional effect & MCR (\%) & $F$ & $P$ \\
\hline 2012 & & & & \\
ST & 0.20 & 20 & 3.26 & $0.002^{* *}$ \\
C+S & 0.11 & 11 & 1.94 & $0.030^{*}$ \\
CS & 0.07 & 7 & 1.26 & 0.202 \\
PD & 0.06 & 6 & 1.16 & 0.336 \\
PH & 0.06 & 6 & 1.09 & 0.386 \\
SM & 0.06 & 6 & 1.12 & 0.360 \\
SOC & 0.04 & 4 & 0.66 & 0.728 \\
TN & 0.06 & 6 & 1.05 & 0.402 \\
SR & 0.05 & 5 & 0.97 & 0.454 \\
Total & & 71 & & \\
2013 & & & & \\
ST & 0.14 & 14 & 2.09 & $0.016^{*}$ \\
SM & 0.14 & 9 & 2.32 & $0.028^{*}$ \\
CS & 0.09 & 8 & 1.50 & 0.148 \\
TN & 0.08 & 8 & 1.40 & 0.180 \\
SOC & 0.08 & 6 & 1.47 & 0.154 \\
PD & 0.06 & 6 & 1.22 & 0.280 \\
PH & 0.06 & 4 & 1.27 & 0.288 \\
SR & 0.04 & 5 & 0.83 & 0.570 \\
FS & 0.05 & 74 & 0.86 & 0.532 \\
Total & & & \\
\hline
\end{tabular}

Note: The inertia from the conditional effects was used to calculate the multivariate correlation ratio (MCR), which represents the proportion of variation explained by the individual environmental factors. The sum of all eigenvalues=1.000. ST, soil temperature; SM, soil moisture; CS, coarse sand content; FS, fine sand content; C+S, clay plus silt content; SOC, soil organic carbon; TN, total nitrogen content; PD, plant density; PH, plant height; SR, species richness. ${ }^{*}$ and ${ }^{* *}$ mean significance at $P<0.05$ and $P<0.01$ levels, respectively.

ecosystems (Zuo et al., 2008, 2010; Han et al., 2014). Furthermore, a remarkably lower herbaceous density in 2013 was found relative to 2012 in all dune microhabitats. It was suggested that soil heterogeneity caused by rainfall pattern could have an effect on the inter-annual distribution of plant performances including seed germination among dune microhabitats in sand dune ecosystems (Jackson et al., 1990). On the other hand, there was properly an opportunistic strategy in seed germination responding to rainfall changes in arid regions according to Maestre et al. (2003).

The ground-active arthropods were very sensitive to the changes in the abiotic and biotic conditions and rainfall pattern, and they were expected to be affected by the varying microhabitats across dune slopes along with rainfall pattern (Staley et al., 2007; Liu et al., 2014). In this study, different taxa were found within specific microhabitats along dune slopes, and were dependent much on rainfall changes as a result of distinctive ecological attributes and adaptations (Staley et al., 2007), which was inconsistent with the first hypothesis. Firstly, the abundant distribution of both Carabidae and Tenebrionidae families along dune slops was found to be similar between 2012 and 2013. This result could be critically dependent upon optimal conditions of soil moisture, temperature and plant performances for their oviposition, eggs, hatching and additional movement for prey in specific microhabitats along dune slopes (Frampton et al., 2000; Liu et al., 2009). Consequently, the Carabidae family could prefer to live in the microhabitats at dune midslope, whiles the Tenebrionidae family could prefer to live in the microhabitats at both dune midslope and top.

Secondly, the abundant distribution of Melolonthidae, Glaphyridae and Formicidae families along dune slops was markedly dependent on inter-annual rainfall pattern. This result was in agreement with Irmler (2003) who reported that the observed changes in ecological parameters of ground beetle assemblage could be taken rather as manifestation of natural fluctuations of yearly 
climatic conditions. For example, the distinctive abundance distribution of Melolonthidae and Glaphyridae family between 2012 and 2013 was attributable to their distributions among dune microhabitats in spring seasons. In dry spring of 2013 in comparison to 2012, the high hatching rate of the Melolonthidae family could homogenize their abundance distribution pattern among dune microhabitats (Nummelin and Fürsch, 1992; Porhajašová et al., 2008; Rainio, 2013). Comparably, the high hatching rate of the Glaphyridae family could heterogenize their abundance distribution pattern among dune microhabitats. The Glaphyridae family was found to prefer dune bottom in comparison to dune top and midslope (Rainio, 2013). It was suggested that rainfall changes (especially in spring) showed a strong influence on their abundance distribution among dune microhabitats. It was reported that the spring oviposition and hatching of ground-active arthropods could determine their behavior and population sizes for the whole year (Parker and Nally, 2001; Staley et al., 2007). In addition, these two families with different ecological adaptations indicated selective and distinctive responses to rainfall-induced dune microhabitats (Zheng and Gui, 2004; Liu, 2012).

However, a significantly greater abundance of family Formicidae occurred at dune top in 2012, whereas at dune bottom in 2013. It was suggested that the ants were susceptible to rainfall changes, and would migrate to their recognized habitats when the soil environment and the preferable habitats among dune microhabitats was discriminative with rainfall changes (Canepuccia et al., 2009). In wet year 2012, the ants preferred to live at dune top with relatively lower soil moisture content and greater soil coarse sand content, whereas in the 2013 with uneven rainfall pattern they preferred to live in the microhabitats at dune bottom with improved soil conditions including soil moisture and temperature as well as soil seed bank (de Bruyn, 1999; Han et al., 2014), which suggested that different taxonomical arthropods could increase or decrease when the soil was rewetted along with rainfall changes.

It was noticeably that no significant differences in total abundance, taxa richness and Shannon index were found either among dune microhabitats averaged on three sampling seasons or within each season timing. This finding was in disagreement with the spatial distribution of soil properties and plant performances along dune slopes observed above. It suggested that the spatial distribution of ground-active arthropods along dune slopes could be mediated by those taxa exposed at soil surface under rainfall changes. Given that our study area was in a small-scale dune slopes, the rainfall increase could translate into changes in microhabitats in relation to soil water levels (Isla and Gaido, 2001; Canepuccia et al., 2007). Soil moisture content due to additional rainfall could diminish the areal extent of terrestrial habitats and habitat diversity on a local scale, with strong consequences for the native fauna (Canepuccia et al., 2008). On such a small scale, i.e. within the given locality, the mobility of organisms was dictated behaviorally by the patchy microhabitats and by the non-random use of different patch types, relative to their availability (Holland et al., 2005; Mazía et al., 2006).

In addition, there could be a compensation effect of abundant distribution between these taxa along dune slope through seasonal rhythm as a result of rainfall changes (Agrawal, 1986). In dry spring of 2013, total abundance and taxa richness were markedly higher at dune bottom, where markedly greater soil moisture content and lower soil temperature were attractive for most arthropod taxa and their performances (Table 3). In this case, the dune bottom could be the "remaining habitat" (Staley et al., 2007) for these ground-active arthropods to dwell in dry spring, as hypothesized. The choice among dune microhabitats seemed to be related not only to the capabilities of dispersers, but also to the quality of the remaining habitats (Driscoll, 2004). The oviposition and hatching of ground-active arthropods occurred at dune bottom since the females were likely to be responding directly to soil moisture content in dry spring (Parker and Nally, 2002). This was consistent with the suggestion of Eyre et al. (1989) that soil water content was an important factor influencing the distribution of ground-active arthropods such as Carabid assemblages in European grasslands. Consequently, under dry climatic conditions, the "remaining habitat" at dune bottom probably would become a "reserves" (i.e. shelter) for the conservation of ground-active arthropods (Zhao and Liu, 2013) among dune microhabitats.

In wet summer of 2013, however, only total abundance differed markedly among dune 
microhabitats, which was ascribed to the much contribution of family Labiduridae, Carabidae, and Melolonthidae with high mobile capability (Zheng and Gui, 2004). In the case of fairly high rainfall amount $(106.5 \mathrm{~mm})$ in summer, the optimal living conditions at dune midslope could be provided for their activities and oviposition (Lindberg, 2003). The soil environments at dune top were susceptibly disturbed by wind blast, whereas soil moisture at dune bottom was too high (i.e. extreme wet conditions) to dwell in for these families (Breckle et al., 2008). At dune midslope microhabitats most arthropod individuals with highly mobile capability could be able to expand their home ranges (Andrén, 1994) and acquire resources by means of free movement (Dunning et al., 1992).

In autumn 2013, total abundance, taxa richness and the Shannon index were also found to be markedly higher at dune midslope in comparison to the other dune microhabitats. The microsite at dune midslope, standing between dune top and bottom microhabitats, enhanced the frequencies of captures of ground-active arthropods by pitfall trapping set in addition to optimal living conditions (Liu et al., 2013). Together, it was a reflective of edge effect on ground-arthropods at small scale, and could simultaneously compensate the effect of other changing microhabitats (i.e. dune top and bottom) along dune slope with seasonal changes from spring to autumn (Li et al., 2012).

As a whole, the ground-active arthropods was dynamic in time, seasonally and yearly, which was in accordance with other studies (Sackmann and Flores, 2009; Liu et al., 2013), suggesting specific responses of ground arthropods to intra- and inter-annual precipitation changes (Liu et al., 2014). Seasonal and yearly rainfall and temperature changes directly caused the abiotic changes that markedly influence the phenology and their feeding activities of arthropods (Sackmann and Flores, 2009; Liu, 2012). Within the year, the phenology was an important biological attribute of arthropods due to their adaptations to local environmental conditions (Canepuccia et al., 2009). The phenology of arthropod groups due to birth/death dynamics and/or diapause could provoke changes in abundance throughout the whole year (Doblas-Miranda et al., 2007).

The inter-annual rainfall pattern could mediate the seasonal rhythm of ground-active arthropods among dune microhabitats. Rainfall played important roles in provoking population fluctuations and generating spatial synchrony of population dynamics (Lima et al., 2002; Sala, 2006). Changes in rainfall regimes might affect species up to the entire ecosystem level by altering biotic interactions (Martin, 2001; Duffy, 2003). In sand dune ecosystems, productivity pulses occurring in rainy periods, affected and followed by bottom-up effects of climate conditions which occurred with a time lag through the food web (Ostfeld and Keesing, 2000; Arim et al., 2007; Farias and Jaksic, 2007; Liu et al., 2014), as compared with the spatial distribution of soil properties and plant performances among dune microhabitats. The results from the plot of RDA (Fig. 4; Table 3) could confirm this point, supporting that soil temperature and soil clay plus silt content were the key factors in 2012, whereas soil temperature and moisture content were the different key factors in 2013 in structuring the community structure of ground-active arthropods.

\section{Conclusions}

The variations of ground-active arthropods were higher than those of soil properties and plant performances in response to rainfall-induced dune microhabitats. The spatial distribution of taxonomic structure among dune microhabitats depended much on inter-annual rainfall changes, and indicating a strong dynamic with time. However, the spatial distribution of community indices among dune microhabitats was much dependent on intra-annual rainfall changes that were regulated by inter-annual rainfall changes. It suggested that the spatial distribution of ground-arthropods among the small-scale dune microhabitat could be vulnerably regulated by climatic factors such as rainfall changes. Taxonomic structure differed much from community structure of ground-arthropods in response to rainfall-induced dune microhabitats. More focus should be given on the effect of rainfall changes on the management and conservation of ground-active arthropods among dune microhabitats in desertified steppe ecosystems. 


\section{Acknowledgements}

This research was supported by the Science Research Foundation of Ningxia Higher Education (NGY2015053), Ningxia Natural Science Foundation (NZ15025), and the National Natural Science Foundation of China (41101050). Many thanks are given to Ningxia Meteorological Bureau for providing climatic data. We thank the two anonymous reviewers for their valuable comments on the manuscript.

\section{References}

Agrawal R K. 1986. On the compensation effect. Journal of Thermal Analysis, 31(1): 73-86.

Andrén H. 1994. Effects of habitat fragmentation on birds and mammals in landscapes with different proportions of suitable habitat: a review. Oikos, 71(3): 355-366.

Arim M, Marquet P A, Jaksic F M. 2007. On the relationship between productivity and food chain length at different ecological levels. The American Naturalist, 169(1): 62-72.

Breckle S W, Yair A, Veste M. 2008. Arid Dune Ecosystems: The Nizzana Sands in the Negev Desert. Berlin Heidelberg: Springer-Verlag.

Canepuccia A D, Isacch J P, Gagliardini D A, et al. 2007. Waterbird response to changes in habitat area and diversity generated by rainfall in a SW Atlantic coastal lagoon. Waterbirds, 30(4): 541-553.

Canepuccia A D, Farias A A, Escalante A H, et al. 2008. Differential responses of marsh predators to rainfall-induced habitat loss and subsequent variations in prey availability. Canadian Journal of Zoology, 86(5): 407-418.

Canepuccia A D, Cicchino A C, Escalante A H, et al. 2009. Differential responses of marsh arthropods to rainfall-induced habitat loss. Zoological Studies, 48(2): 174-183.

de Bruyn L A L. 1999. Ants as bio-indicators of soil function in rural environments. Agriculture, Ecosystems \& Environment, 74(1-3): 425-441.

Dijkstra F A, Augustine D J, Brewer P, et al. 2012. Nitrogen cycling and water pulses in semiarid grasslands: are microbial and plant processes temporally asynchronous?. Oecologia, 170(3): 799-808.

Doblas-Miranda E, Sánchez-Piñero F, González-Megías A. 2007. Soil macroinvertebrate fauna of a Mediterranean arid system: composition and temporal changes in the assemblage. Soil Biology and Biochemistry, 39(8): 1916-1925.

Doblas-Miranda E, Sánchez-Piñero F, González-Megías A. 2009. Different microhabitats affect soil macro-invertebrate assemblages in a Mediterranean arid ecosystem. Applied Soil Ecology, 41(3): 329-335.

Driscoll D A. 2004. Extinction and outbreaks accompany fragmentation of a reptile community. Ecological Applications, 14(1): $220-240$

Duffy J E. 2003. Biodiversity loss, trophic skew and ecosystem functioning. Ecology Letters, 6(8): 680-687.

Dunning J B, Danielson B J, Pulliam H R. 1992. Ecological processes that affect populations in complex landscapes. Oikos, 65(1): $169-175$.

Eyre M D, Luff M L, Rushton S P, et al. 1989. Ground beetles and weevils (Carabidae and Curculionoidea) as indicators of grassland management practices. Journal of Applied Entomology, 107(1-5): 508-517.

Farias A A, Jaksic F M. 2007. Effects of functional constraints and opportunism on the functional structure of a vertebrate predator assemblage. Journal of Animal Ecology, 76(2): 246-257.

Frampton G K, Van den Brink P J, Gould P J L. 2000. Effects of spring drought and irrigation on farmland arthropods in southern Britain. Journal of Applied Ecology, 37(5): 865-883.

Han R Y, Chen Y Y, Li W X. 2014. The distribution and relationships of ground vegetation, soil seed bank and soil water content of fixed sand under different micro-landform conditions. Pratacultural Science, 31(10): 1825-1832. (in Chinese)

Holland J D, Fahrig L, Cappuccino N. 2005. Body size affects the spatial scale of habitat-beetle interactions. Oikos, 110(1): $101-108$.

Holt R D, Lawton J H, Polis G A, et al. 1999. Trophic rank and the species-area relationship. Ecology, 80(5): $1495-1504$.

Institute of Soil Sciences, Chinese Academy of Sciences (ISSCAS). 1978. Physical and Chemical Analysis Methods of Soils. Shanghai: Shanghai Science Technology Press. (in Chinese)

Irmler U. 2003. The spatial and temporal pattern of carabid beetles on arable fields in northern Germany (Schleswig-Holstein) and their value as ecological indicators. Agriculture, Ecosystems \& Environment, 98(1-3): 141-151.

Isla F I, Gaido E S. 2001. Geological evolution of the Mar Chiquita lagoon. In: Iribarne O O. Mar Chiquita Biosphere Reserve: Physical, Biological and Ecological Characteristics. Mar del Plata, Argentina: Editorial Martin Press, 19-30. (in Spanish)

Jackson R B, Manwaring J H, Caldwell M M. 1990. Rapid physiological adjustment of roots to localized soil enrichment. Nature, 344(6261): 58-60. 
Kidron G J, Yair A. 1997. Rainfall-runoff relationship over encrusted dune surfaces, Nizzana, western Negev, Israel. Earth Surface Processes and Landforms, 22(12): 1169-1184.

Kidron G J. 1999. Differential water distribution over dune slopes as affected by slope position and microbiotic crust, Negev Desert, Israel. Hydrological Processes, 13(11): 1665-1682.

Lavelle P, Spain A V. 2001. Soil Ecology. Amsterdam: Kluwer Scientific Publications.

Lepš J, Šmilauer P. 2003. Multivariate Analysis of Ecological Data using CANOCO. Cambridge: Cambridge University Press.

Li J, Shi J, Luo Y Q, et al. 2012. Plant and insect diversity along an experimental gradient of larch-birch mixtures in Chinese boreal forests. Turkish Journal of Agriculture and Forestry, 36(2): 247-255.

Lima M, Stenseth N C, Jaksic F M. 2002. Food web structure and climate effects on the dynamics of small mammals and owls in semi-arid Chile. Ecology Letters, 5(2): 273-284.

Lindberg N. 2003. Soil fauna and global change: responses to experimental drought, irrigation, fertilisation and soil warming. PhD Dissertation. Uppsala: Swedish University of Agricultural Sciences.

Liu J L, Zhao W Z, Li F R. 2014. An overview on the distribution pattern of soil animal responses to precipitation pulses in arid desert ecosystems. Journal of Desert Research, 34(5): 1337-1342. (in Chinese)

Liu R T, Zhao H L, Zhao X Y, et al. 2009. Soil macrofaunal response to sand dune conversion from mobile dunes to fixed dunes in Horqin Sandy Land, northern China. European Journal of Soil Biology, 45(5-6): 417-422.

Liu R T. 2012. Relationships between soil fauna and rainfall change in desert steppe: A review. Chinese Journal of Ecology, 31(3): 760-765. (in Chinese)

Liu R T, Zhu F, Song N P, et al. 2013. Seasonal distribution and diversity of ground arthropods in microhabitats following a shrub plantation age sequence in desertified steppe. PLoS One, 8(10): e77962.

Maestre F T, Cortina J, Bautista S, et al. 2003. Small-scale environmental heterogeneity and spatiotemporal dynamics of seedling establishment in a semiarid degraded ecosystem. Ecosystems, 6(7): 630-643.

Martin T E. 2001. Abiotic vs. biotic influences on habitat selection of coexisting species: climate change impacts?. Ecology, 82(1): $175-188$.

Mazía C N, Chaneton E J, Kitzberger T. 2006. Small-scale habitat use and assemblage structure of ground-dwelling beetles in a Patagonian shrub steppe. Journal of Arid Environments, 67(2): 177-194.

Nummelin M, Fürsch H. 1992. Coccinellids of the Kibale forest, Western Uganda: a comparison between virgin and managed sites. Tropical Zoology, 5(2): 155-166.

Olff H, Ritchie M E. 1998. Effects of herbivores on grassland plant diversity. Trends in Ecology \& Evolution, 13(7): $261-265$.

Ostfeld R S, Keesing F. 2000. Pulsed resources and community dynamics of consumers in terrestrial ecosystems. Trends in Ecology \& Evolution, 15(6): 232-237.

Pan D Y, Bouchard A, Legendre P, et al. 1998. Influence of edaphic factors on the spatial structure of inland halophytic communities: a case study in China. Journal of Vegetation Science, 9(6): 797-804.

Parker M, Nally R M. 2002. Habitat loss and the habitat fragmentation threshold: an experimental evaluation of impacts on richness and total abundances using grassland invertebrates. Biological Conservation, 105(2): 217-229.

Pen-Mouratov S, Hu C, Hindin E, et al. 2010. Effect of sand-dune slope orientation on soil free-living nematode abundance and diversity. Helminthologia, 47(3): 179-188.

Porhajašová J, Petřvalský V, Šustek Z, et al. 2008. Long-termed changes in ground beetle (Coleoptera: Carabidae) assemblages in a field treated by organic fertilizers. Biologia, 63(6): 1184-1195.

Pugnaire F I, Haase P, Puigdefábregas J. 1996. Facilitation between higher plant species in a semiarid environment. Ecology, 77(5): 1420-1426.

Rainio J, 2013. Seasonal variation of Carabid beetle (Coleoptera: Carabidae) abundance and diversity in Ranomafana National Park, Madagascar. Journal of Entomology and Zoology Studies, 1(5): 92-98.

Rozé F, Lemauviel S. 2004. Sand dune restoration in North Brittany, France: a 10-year monitoring study. Restoration Ecology, 12(1): 29-35.

Sabino C M, Teixeira F P F, Zee D M W, et al. 1993. Restoring the beach profile with vegetation. In: Magoon O T, Wilson W S, Converse H, et al. Coastal Zone 93. New York: American Society of Civil Engineers, 2312-2323.

Sackmann P, Flores G E. 2009. Temporal and spatial patterns of tenebrionid beetle diversity in NW Patagonia, Argentina. Journal of Arid Environments, 73(12): 1095-1102.

Sala E. 2006. Top predators provide insurance against climate change. Trends in Ecology \& Evolution, 21(9): 479-480.

Sebastiá M T. 2004. Role of topography and soils in grassland structuring at the landscape and community scales. Basic and Applied Ecology, 5(4): 331-346.

Song N P, Yang M X, Wang L, et al. 2014. Monthly variation in soil moisture under Caragana intermedia stands grown in 
desert steppe. Chinese Journal of Ecology, 33(10): 2618-2624. (in Chinese)

Spaargaren O C, Deckers J. 1998. The world reference base for soil resources. In: Schulte A, Ruhiyat D. Soils of Tropical Forest Ecosystems. Berlin Heidelberg: Springer, 1001-1002.

Staley J T, Mortimer S R, Morecroft M D, et al. 2007. Summer drought alters plant-mediated competition between foliar- and root-feeding insects. Global Change Biology, 13(4): 866-877.

Thomas C D. 2000. Dispersal and extinction in fragmented landscapes. Proceedings of the Royal Society of London, 267(1439): 139-145.

Wardle D A, Bardgett R D, Klironomos J N, et al. 2004. Ecological linkages between aboveground and belowground biota. Science, 304(5677): 1629-1633.

Yin W Y. 2001. Pictorial Keys to Soil Animals of China. Beijing: Science Press. (in Chinese)

Zhao H L, Liu R T. 2013. The "bug island" effect of shrubs and its formation mechanism in Horqin Sand Land, Inner Mongolia. Catena, 105: 69-74.

Zheng L Y, Gui H. 2004. Insect Classification. Nanjing: Nanjing Normal University Press. (in Chinese)

Zuo X A, Zhao H L, Zhao X Y, et al. 2008. Plant distribution at the mobile dune scale and its relevance to soil properties and topographic features. Environmental Geology, 54(5): 1111-1120.

Zuo X A, Zhao X Y, Zhao H L, et al. 2010. Spatial pattern and heterogeneity of soil organic carbon and nitrogen in sand dunes related to vegetation change and geomorphic position in Horqin Sandy Land, Northern China. Environmental Monitoring and Assessment, 164(1-4): 29-42.

Zuo X A, Wang S K, Zhao X Y, et al. 2012. Effect of spatial scale and topography on spatial heterogeneity of soil seed banks under grazing disturbance in a sandy grassland of Horqin Sand Land, Northern China. Journal of Arid Land, 4(2): 151-160. 